\title{
The association of CCAT2 rs6983267 SNP with MYC expression and progression of uterine cervical cancer in the Polish population
}

\author{
Sebastian Łaźniak ${ }^{1}$. Anna Lutkowska ${ }^{1} \cdot$ Żaneta Wareńczak-Florczak $^{2,3}$ - Anna Sowińska ${ }^{4}$ - Alexander Tsibulski ${ }^{1}$. \\ Andrzej Roszak $^{2,3} \cdot$ Stefan Sajdak ${ }^{5}$ Pawel P. Jagodziński ${ }^{1}$ (1)
}

Received: 26 July 2017 / Accepted: 5 March 2018 / Published online: 10 March 2018

(c) The Author(s) 2018. This article is an open access publication

\begin{abstract}
Purpose Previous studies have reported a significant contribution of NC_000008.10:g.128413305 G>T (rs6983267) singlenucleotide polymorphism (SNP) in the MYC enhancer region to the susceptibility of various cancers. However, the role of rs6983267 SNP in cervical cancer (CC) development and progression has not been demonstrated to date. Therefore, we evaluated the role of rs6983267 SNP in MYC expression in cervical cancers and non-cancerous cervical tissues. In addition, we assessed the role of this SNP in the development and progression of CC.

Methods Using high-resolution melting analysis, we evaluated rs6983267 SNP frequency in women diagnosed with cervical squamous cell carcinoma (SCC) $(n=481)$ and controls $(n=502)$ in a Polish Caucasian population. Logistic regression analysis was employed to adjust for the effects of age, parity, oral contraceptive use, tobacco smoking, and menopausal status. Results Dividing patients based on clinical characteristics demonstrated an association of the rs6983267 genotype with tumor stage III and grade of differentiation G2 and G3. The $p$ trend value calculated for the rs6983267 SNP in patients with stage III was 0.0006 . We also observed a significant contribution of rs6983267 SNP to tumor grade of differentiation G2 and G3. Additional contributors were oral contraceptive use, smoking, and postmenopausal age. We found statistically significant increase of MYC transcript levels in cervical SCC tissues from carriers of the GG vs. T/T $(p<0.00001)$, G/T vs. $\mathrm{T} / \mathrm{T}(p=0.0002)$, and in the non-cancerous cervical tissues from carriers of the GG vs. T/T $(p=0.00046)$.

Conclusion The rs6983267 SNP may contribute to the increased MYC expression as well as the spread and rapid growth of cervical SCC as compared to lower grade carcinomas.
\end{abstract}

Keywords Cervical squamous cell carcinoma $\cdot$ MYC $\cdot$ Polymorphism

Electronic supplementary material The online version of this article (https://doi.org/10.1007/s00404-018-4740-6) contains supplementary material, which is available to authorized users.

Pawel P. Jagodziński

pjagodzi@am.poznan.pl

1 Department of Biochemistry and Molecular Biology, Poznań University of Medical Sciences, 6 Święcickiego St., 60-781 Poznan, Poland

2 Department of Radiotherapy and Gynecological Oncology, Greater Poland Cancer Center, Pozna, Poland

3 Department of Electroradiology, Poznań University of Medical Sciences, Poznan, Poland

4 Department of Computer Science and Statistics, Poznań University of Medical Sciences, Poznan, Poland

5 Clinic of Gynecological Surgery, Poznań University of Medical Sciences, Poznan, Poland

\section{Introduction}

Cervical cancer (CC) is fourth among the common malignancies, which affect women worldwide [1]. The cervix is composed of an ectocervix which is covered by stratified squamous epithelium, and an endocervical canal consisting of mucus-secreting columnar epithelium $[1,2]$. The ectocervix is more predisposed to transformation and development of squamous cell carcinoma (SCC), while the endocervix is more predisposed to adenocarcinomas [1,2]. Less common histological subtypes of CC include adenosquamous, small cell/neuroendocrine, serous papillary, and clear cell carcinomas of the cervix $[1,2]$. Cervical SCC account for approximately $80 \%$ of invasive CC cases [1]. Virtually, all cases of $\mathrm{CC}$ result from infection with the oncogenic strains of human papillomavirus (HPV) [3, 4]. The majority of HPV infections are short-lived and resolve spontaneously [5-7]. 
However, in some individual cases, permanent infection will lead to development of a precancerous lesion, known as cervical intraepithelial neoplasia or adenocarcinoma in situ [5] Additional factors increasing the likelihood of the development of CC include tobacco smoking, long-term oral contraceptive use, high parity, early sexual intercourse, pollutants, and co-infection with type 2 herpes simplex virus or the human immunodeficiency virus [8-10].

Cervical carcinoma development displays strong genetic predisposition, especially with history of cancer in a firstdegree relative [11-13] Genome-wide association studies (GWAS) demonstrated MHC loci as major genetic components in the development of CC [14-16]. Various previously studied polymorphisms failed to reach GWAS-statistical significance, but, nevertheless, they may still contribute to the progression of CC [17].

Recently, it has been reported that the integrated HPV fragment creates long-distance interactions with MYC gene and 8q24.22 region, therefore, increasing the allele-specific MYC expression in cervical cancer [18] HeLa cells. The previous studies demonstrated a significant contribution of NC_000008.10:g.128413305 G>T (rs6983267) singlenucleotide polymorphism (SNP) in the MYC enhancer region to the susceptibility to various cancers [19-25]. However, the role of rs6983267 SNP in CC development and progression has not been demonstrated to date. In our study, we assessed the prevalence of rs6983267 SNP in women with cervical SCC in the Polish Caucasian population. We also evaluated the distribution of rs6983267 in stages I-IV and the differentiation grades of cervical SCC.

\section{Methods}

\section{Study population}

The studied subjects included 481 patients diagnosed with cervical SCC, with stage and grade of differentiation evaluated according to the International Federation of Gynecology and Obstetrics (FIGO) classification system and World Health Organization (Table 1). Patient data and primary cervical SCC tissue samples were obtained from subjects enrolled between March 2008 and December 2016 at the Department of Radiotherapy of the Greater Poland Cancer Center in Poznań, Poland (Fig. 1). The control group included 502 healthy females randomly selected during medical examinations at the Institute of Mother and Child, Warsaw (Table 1).

Information regarding the parity of at least one, oral contraceptive use, active tobacco smoking within the last 12 months, and menopausal status was obtained as part of the control and patient history.
Table 1 Clinical and demographic characteristics of patients with cervical squamous cell carcinoma and controls

\begin{tabular}{|c|c|c|c|}
\hline Characteristic & Patients $(n=481)$ & Controls $(n=502)$ & $p^{\mathrm{b}}$ \\
\hline $\begin{array}{l}\text { Mean age } \\
\quad(\text { years }) \pm \mathrm{SD}^{\mathrm{a}}\end{array}$ & $51.4 \pm 9.6$ & $51.7 \pm 9.1$ & \\
\hline \multicolumn{4}{|l|}{ Tumor stage } \\
\hline IA & $62(12.8 \%)$ & & \\
\hline IB & $61(12.7 \%)$ & & \\
\hline IIA & $59(12.3 \%)$ & & \\
\hline IIB & $57(11.9 \%)$ & & \\
\hline IIIA & $152(31.6 \%)$ & & \\
\hline IIIB & $61(12.7 \%)$ & & \\
\hline IVA & $14(2.9 \%)$ & & \\
\hline IVB & $15(3.1 \%)$ & & \\
\hline \multicolumn{4}{|l|}{ Histological grade } \\
\hline G1 & $151(31.4 \%)$ & & \\
\hline $\mathrm{G} 2$ & $101(21.0 \%)$ & & \\
\hline G3 & $167(34.7 \%)$ & & \\
\hline Gx & $62(12.9 \%)$ & & \\
\hline \multicolumn{4}{|l|}{ Parity } \\
\hline Never & $61(12.68 \%)$ & $55(10.96 \%)$ & \\
\hline Ever & $420(87.32 \%)$ & $447(89.04 \%)$ & $0.402^{\mathrm{b}}$ \\
\hline \multicolumn{4}{|c|}{ Oral contraceptive pill use } \\
\hline Never & $262(54.47 \%)$ & $289(57.57 \%)$ & \\
\hline Ever & $219(45.53 \%)$ & $213(42.43 \%)$ & $0.328^{\mathrm{b}}$ \\
\hline \multicolumn{4}{|l|}{ Tobacco smoking } \\
\hline Never & $308(64.03 \%)$ & $332(66.14 \%)$ & \\
\hline Ever & $173(35.97 \%)$ & $170(33.86 \%)$ & $0.489^{\mathrm{b}}$ \\
\hline \multicolumn{4}{|l|}{ Menopausal status } \\
\hline Premenopausal & $170(35.34 \%)$ & $194(38.65 \%)$ & \\
\hline Postmenopausal & $311(64.66 \%)$ & $308(61.35 \%)$ & $0.284^{b}$ \\
\hline \multicolumn{4}{|l|}{ HPV genotypes } \\
\hline 16 and 18 & $343(71.3 \%)$ & & \\
\hline $\begin{array}{l}16,18,31,33,35 \\
39,45,51,52,56 \\
58,59 \text { and } 68\end{array}$ & $389(80.9 \%)$ & & \\
\hline
\end{tabular}

${ }^{a}$ Age at first diagnosis

${ }^{\mathrm{b}}$ Chi-squared, $p$ statistical $p$ value

\section{Tissue samples}

The primary SCC tissue samples were obtained from 51 patients with mean age of $52.4 \pm 9.6$ years and classified as stage III at the time of surgery. The non-cancerous cervical tissue samples were obtained from 52 women with a mean age of $51.8 \pm 9.7$ years with uterine leiomyomas undergoing uterine surgical resection in the Clinic of Gynecological Surgery, University of Medical Sciences, Poznań, Poland. A portion of the tissue sample was immediately snap-frozen in liquid nitrogen and stored at $-80^{\circ} \mathrm{C}$ until RNA isolation was performed. 


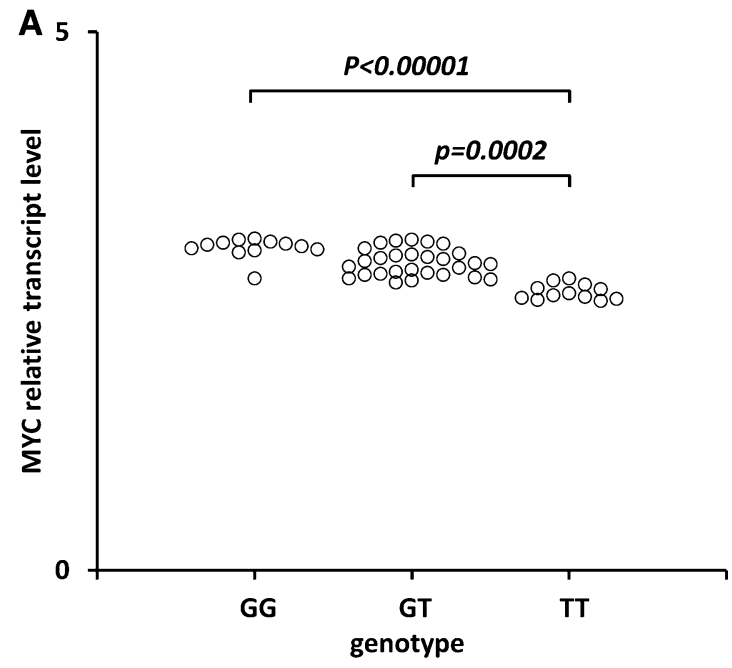

Fig. 1 Effect of the rs6983267 SNP on MYC transcript levels in cancerous cervical tissues (a) and non-cancerous tissues (b). Frozen tissue was homogenized, followed by total RNA isolation. Quantitative analyses of MYC transcript levels were performed by qRT-PCR

\section{Study ethics}

All the patients and controls were Polish Caucasians and written consent was obtained from all participating individuals. The study procedures were approved by the Local Ethical Committee of the Poznan University of Medical Sciences (reference number of ethical approval: 285/16 and 566/16).

\section{Genetic analysis}

DNA was isolated from peripheral blood cells via a saltingout procedure. The primers were designated using Oligo 7.6 software (DBA Oligo, Inc., Colorado Springs, CO). The NC_000008.10:g.128413305 G>T polymorphism DNA fragment $(170 \mathrm{bp}$ ) was amplified using the primers (forward 5' TAACCTCTTCCTATCTCA 3' and reverse 5' AAATAA AGTCAATAGCACAT 3'). The rs6983267 SNP was then genotyped via high-resolution melting (HRM) curve analysis using HOT FIREPol EvaGreen (Solis BioDyne, Tartu, Estonia) with a LightCycler 480 system (Roche Diagnostics, Mannheim, Germany). The presence of this SNP was reanalyzed by Sanger sequencing analyses of arbitrarily chosen samples, comprising $10 \%$ of the samples from both cases and controls. The concordance rate between HRM and sequencing was $100 \%$.

\section{Reverse transcription and quantitative real-time PCR (qRT-PCR) analysis of MYC transcript levels in cervical SCC and non-cancerous tissues}

Frozen SCC and non-cancerous tissues were homogenized and total RNA was isolated according to the method of

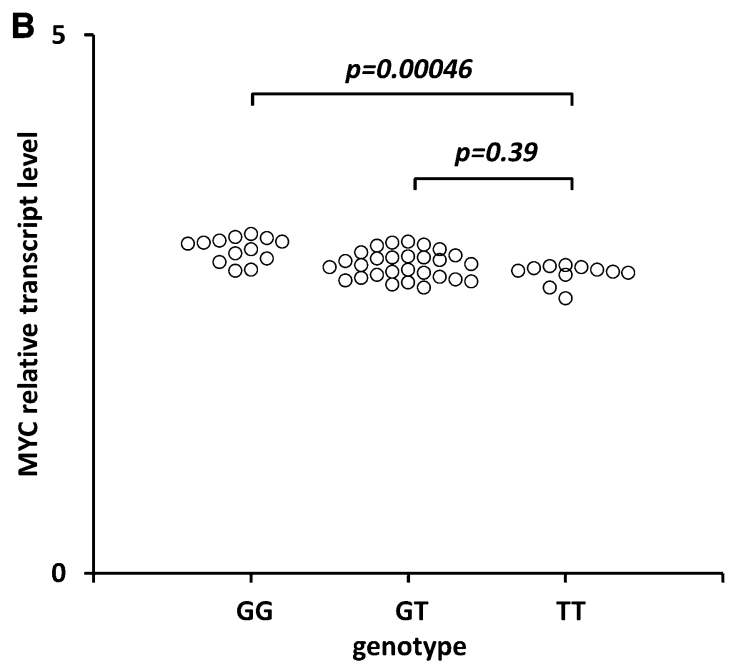

using the SYBR Green I system. The quantity of MYC transcript levels in each sample was standardized by the geometric mean of references using HMBS and B2M cDNA levels. Kruskal-Wallis test with a'Dunn's post hoc

Chomczyński and Sacchi [26]. RNA quality was determined spectrophotometrically using a BioPhotometer ${ }^{\circledR}$ from Eppendorf AG (Hamburg, Germany) and agarose gel electrophoresis. RNA samples were treated with DNase I, quantified, and reverse-transcribed (RT) into complimentary DNA (cDNA) using the Moloney Murine Leukemia Virus (M-MLV) from Invitrogen (Life Technologies, Carlsbad, CA) (Supplementary data 1).

Quantitative analysis of MYC cDNA isoforms (Supplementary data 1) was performed by Light $\mathrm{Cycler}^{\circledR} 480 \mathrm{II}$ Real-Time PCR System (Roche Diagnostics GmbH, Mannheim, Germany), using SYBR Green I as detection dye. MYC cDNA was quantified using the relative quantification method with a calibrator. The calibrator was prepared with a cDNA mix from all cDNA samples and consecutive dilutions were used to create a standard curve. For amplification, $1 \mu \mathrm{l}$ of cDNA solution was added to $9 \mu 1$ of LightCycler 480 SYBR Green I Master Mix (Roche Diagnostics GmbH, Mannheim, Germany) and primers (Supplementary data 1).

The quantity of MYC transcript in each sample was standardized by the geometric mean of reference transcript levels: hydroxymethylbilane synthase (HMBS) and beta2-microglobulin (B2 M). The PCR amplification efficiency for target and reference cDNA was determined using different standard curves created by consecutive dilutions of the cDNA template mixture. The MYC cDNA, HMBS, and B2 $\mathrm{M}$ cDNA were amplified using the primer pairs presented in Supplementary data 1. The MYC mRNA levels were expressed as multiples of these cDNA concentrations in the calibrator. 


\section{Statistical analysis}

The distinction in genotypic prevalence between the patients and controls and their genotype deviation from Hardy-Weinberg (HW) equilibrium were evaluated using a $\chi^{2}$ test. The rs6983267 SNP was tested for association with cervical SCC using the Cochran-Armitage $p$ trend test $\left(p_{\text {trend }}\right)$. The $\chi^{2}$ and Fisher's exact tests were used to determine the differences in genotypic distributions between the patients and controls. The odds ratio (OR) and $95 \%$ confidence intervals (95\% CI) were also calculated. A logistic regression analysis was used to adjust for the effect of confounders such as age, parity, oral contraceptive use, tobacco smoking, and menopausal status. A $p$ value of $<0.05$ was considered statistically significant. Statistical analysis of comparing MYC transcript levels between the G/G vs. T/T and T/G vs. T/T genotype carriers was evaluated using the Kruskal-Wallis test with Dunn's post hoc. Statistical analyses were conducted using Statistica version 10, 2011 (Stat Soft, Inc., Tulsa, USA).

\section{Results}

\section{Prevalence of the rs6983267 SNP among all women with cervical SCC and healthy women}

The values for the Chi-square $\left(\chi^{2}\right)$ test of HW equilibrium were 0.119 and 0.188 for the patients and controls, respectively. The statistical evaluation of the rs6983267 genotype distribution in women with SCC and healthy women is stated in Table 2. We did not find a significant association of rs6983267 SNP with all patients with cervical SCC, the $p$ trend value calculated for the rs6983267 polymorphism was $p_{\text {trend }}=0.146$. The logistic regression analysis, which adjusted for the effects of age, parity, oral contraceptive use, tobacco smoking, and menopausal status, also did not demonstrate an association of rs6983267 SNP with cervical SCC (Table 2). For G/G vs. T/T adjusted OR was 1.139 (95\% CI $0.906-1.432, p=0.262$ ), for $\mathrm{T} / \mathrm{G}$ vs. $\mathrm{T} / \mathrm{T}$ adjusted $\mathrm{OR}$ was 1.505 (95\% CI 1.059-2.137, $p=0.056$ ), and for $\mathrm{T} / \mathrm{G}+\mathrm{G} / \mathrm{G}$ vs. T/T adjusted OR was 1.307 (95\% CI $0.938-1.822$, $p=0.113)$.

\section{Prevalence on of the rs6983267 SNP among cervical SCC women for different tumor stages and grade of differentiation.}

Stratification of patients based on clinical characteristics demonstrated an association of the rs6983267 genotype with tumor stages III and grade of differentiation G2 and G3 (Table 2). The $p$ trend value calculated for the rs6983267 SNP in cervical SCC patients with stage III was statistically significant ( $p_{\text {trend }}=0.0006$ ). Adjusting for the effect of age, parity, oral contraceptive use, tobacco smoking, and menopausal status in patients with stage III, the logistic regression analysis revealed that the G/G vs. T/T genotype may be a risk factor of cervical SCC with an adjusted OR 1.659 (95\% CI 1.567-2.381, $p=0.006$ ). There was also significant association with SCC for the T/G vs. T/T genotype, with an adjusted OR 2.604 (95\% CI 1.539-4.406, $p=0.0003$ ) and for the $\mathrm{T} / \mathrm{G}+\mathrm{G} / \mathrm{G}$ vs. T/T genotype, with an adjusted OR 2.356 (95\% CI $1.453-3.820, p=0.0005)$ in stage III patients. In women with differentiation grade $\mathrm{G} 2$, the $p$ trend value calculated for rs6983267 SNP was not statistically significant $\left(p_{\text {trend }}=0.812\right)$. There was also no risk effect of the $\mathrm{G} / \mathrm{G}$ vs. T/T genotype with an adjusted OR 1.257 (95\% CI $0.836-1.889, p=0.269)$. However, we found a risk effect of the T/G vs. T/T genotype with an adjusted OR 2.798 (95\% CI 1.398-5.597, $p=0.004)$ and for $\mathrm{T} / \mathrm{G}+\mathrm{G} / \mathrm{G}$ vs. T/T with an adjusted OR 2.058 (95\% CI 1.090-3.885, $p=0.026$ ).

In patients with grade of differentiation $\mathrm{G} 3$, the $p$ trend value calculated for the rs6983267 SNP was statistically significant $\left(p_{\text {trend }}=0.0068\right)$. We found a risk effect of the T/G vs. G/G genotype, with an adjusted OR 3.032 (95\% CI $1.668-5.510, p=0.0003$ ) and for $\mathrm{T} / \mathrm{G}+\mathrm{G} / \mathrm{G}$ vs. $\mathrm{T} / \mathrm{T}$ with an adjusted OR 2.330 (95\% CI 1.365-3.978, $p=0.002$ ). However, we did not observe significant association for G/G vs. T/T genotype, with an adjusted OR 2.330 (95\% CI $1.365-3.978, p=0.002)$. The logistic regression analysis did not show any association of the rs6983267 SNP with tumor stage I and IV and grade of differentiation G1 and GX (Table 2). Moreover, there was no association of the rs6983267 SNP with HPV strains to neither SCC nor tumor stages I, II, III, and IV and grades of differentiation G1, G2, G3, and GX (data not shown).

\section{Distribution of the rs6983267 SNP among women with SCC and healthy women with history of parity, oral contraceptive use, tobacco smoking, or menopausal status}

Stratification of patients for rs6983267 SNP demonstrated an association of this polymorphism with positive history of oral contraceptive use, smoking, and postmenopausal age (Table 3). The age-adjusted OR for women with a positive history of oral contraceptive use for $\mathrm{G} / \mathrm{G}$ vs. T/T was 1.558 (95\% CI 1.135-2.139, $p=0.0057$ ); and for $\mathrm{T} / \mathrm{G}+\mathrm{G} / \mathrm{G}$ vs. $\mathrm{T} / \mathrm{T}$, the age-adjusted OR was 1.687 (95\% CI 1.048-2.715, $p=0.0309$ ). The age-adjusted OR for women with a history of tobacco smoking for T/G vs. T/T was 2.098 (95\% CI $1.248-3.527,0.005)$. In women of postmenopausal age, we found contribution of rs6983267 SNP to the risk of cervical SCC. The age-adjusted OR for postmenopausal women for 
Table 2 Prevalence of the rs6983267 polymorphism among patients with SCC and controls

\begin{tabular}{|c|c|c|c|c|c|c|c|}
\hline Genotype & Patients (frequency) & Controls (frequency) & Odds ratio $(95 \% \mathrm{CI})$ & $p^{\mathrm{a}}$ & Adjusted odds ratio $(95 \% \mathrm{CI})^{\mathrm{c}}$ & $p$ & $p_{\text {trend }}$ \\
\hline \multicolumn{8}{|l|}{ All } \\
\hline $\mathrm{T} / \mathrm{T}$ & $104(0.21)$ & $126(0.25)$ & Referent & & Referent & & 0.146 \\
\hline $\mathrm{T} / \mathrm{G}$ & $263(0.55)$ & $271(0.54)$ & $1.176(0.862-1.603)$ & 0.306 & $1.505(1.059-2.137)$ & 0.056 & \\
\hline $\mathrm{G} / \mathrm{G}$ & $114(0.24)$ & $105(0.21)$ & $1.315(0.908-1.907)$ & 0.147 & $1.139(0.906-1.432)$ & 0.262 & \\
\hline $\mathrm{G} / \mathrm{T}+\mathrm{G} / \mathrm{G}$ & $377(0.78)$ & $376(0.75)$ & $1.215(0.9031-1.634)$ & 0.198 & $1.307(0.938-1.822)$ & 0.113 & \\
\hline $\mathrm{MAF}^{\mathrm{d}}$ & 0.51 & 0.48 & & & & & \\
\hline \multicolumn{8}{|l|}{ Tumor stage } \\
\hline \multicolumn{8}{|l|}{$\mathrm{IA}+\mathrm{IB}$} \\
\hline $\mathrm{T} / \mathrm{T}$ & $37(0.30)$ & $126(0.25)$ & Referent & - & Referent & - & 0.417 \\
\hline $\mathrm{T} / \mathrm{G}$ & $61(0.50)$ & $271(0.54)$ & $0.767(0.484-1.214)$ & 0.256 & $1.395(0.797-2.440)$ & 0.243 & \\
\hline $\mathrm{G} / \mathrm{G}$ & $25(0.20)$ & $105(0.21)$ & $0.811(0.459-1.433)$ & 0.470 & $1.045(0.739-1.479)$ & 0.801 & \\
\hline $\mathrm{G} / \mathrm{T}+\mathrm{G} / \mathrm{G}$ & $86(0.70)$ & $376(0.75)$ & $0.779(0.504-1.203)$ & 0.259 & $1.180(0.699-1.991)$ & 0.535 & \\
\hline MAF $^{\mathrm{d}}$ & 0.50 & 0.48 & & & & & \\
\hline \multicolumn{8}{|l|}{ IIA + IIB } \\
\hline $\mathrm{T} / \mathrm{T}$ & $33(0.28)$ & $126(0.25)$ & Referent & - & Referent & - & 0.377 \\
\hline $\mathrm{T} / \mathrm{G}$ & $62(0.53)$ & $271(0.54)$ & $0.874(0.545-1.401)$ & 0.575 & $0.712(0.346-1.081)$ & 0.090 & \\
\hline $\mathrm{G} / \mathrm{G}$ & $21(0.18)$ & $105(0.21)$ & $0.764(0.417-1.399)$ & 0.382 & $0.863(0.456-0.964)$ & 0.081 & \\
\hline $\mathrm{G} / \mathrm{T}+\mathrm{G} / \mathrm{G}$ & $83(0.72)$ & $376(0.75)$ & $0.8428(0.5368-1.323)$ & 0.4571 & $0.670(0.274-0.806)$ & 0.096 & \\
\hline $\mathrm{MAF}^{\mathrm{d}}$ & 0.45 & 0.48 & & & & & \\
\hline \multicolumn{8}{|l|}{$\mathrm{IIIA}+\mathrm{IIIB}$} \\
\hline $\mathrm{T} / \mathrm{T}$ & $30(0.14)$ & $126(0.25)$ & Referent & - & Referent & - & 0.0006 \\
\hline $\mathrm{T} / \mathrm{G}$ & $122(0.57)$ & $271(0.54)$ & $1.891(1.203-2.971)$ & 0.0053 & $2.604(1.539-4.406)$ & 0.0003 & \\
\hline $\mathrm{G} / \mathrm{G}$ & $61(0.29)$ & $105(0.21)$ & $2.440(1.468-4.056)$ & 0.0005 & $1.659(1.567-2.381)$ & 0.006 & \\
\hline $\mathrm{G} / \mathrm{T}+\mathrm{G} / \mathrm{G}$ & $183(0.86)$ & $376(0.75)$ & $2.044(2.322-3.160)$ & 0.0011 & $2.356(1.453-3.820)$ & 0.0005 & \\
\hline $\mathrm{MAF}^{\mathrm{d}}$ & 0.57 & 0.48 & & & & & \\
\hline \multicolumn{8}{|l|}{ IVA + IVB } \\
\hline $\mathrm{T} / \mathrm{T}$ & $4(0.14)$ & $126(0.25)$ & Referent & - & Referent & & 0.2592 \\
\hline $\mathrm{T} / \mathrm{G}$ & $18(0.62)$ & $271(0.54)$ & $2.092(0.694-6.311)$ & $0.239^{\mathrm{b}}$ & NA & & \\
\hline $\mathrm{G} / \mathrm{G}$ & $7(0.24)$ & $105(0.21)$ & $2.100(0.598-7.372)$ & $0.354^{\mathrm{b}}$ & NA & & \\
\hline $\mathrm{G} / \mathrm{T}+\mathrm{G} / \mathrm{G}$ & $25(0.86)$ & $376(0.75)$ & $2.094(0.715-6.136)$ & $0.191^{\mathrm{b}}$ & NA & & \\
\hline $\mathrm{MAF}^{\mathrm{d}}$ & 0.55 & 0.48 & & & & & \\
\hline \multicolumn{8}{|c|}{ Differentiation grade } \\
\hline \multicolumn{8}{|c|}{ G1 } \\
\hline $\mathrm{T} / \mathrm{T}$ & $37(0.24)$ & $126(0.25)$ & Referent & - & Referent & - & 0.509 \\
\hline $\mathrm{T} / \mathrm{G}$ & $77(0.51)$ & $271(0.54)$ & $0.968(0.620-1.511)$ & 0.885 & $0.590(0.343-1.014)$ & 0.056 & \\
\hline $\mathrm{G} / \mathrm{G}$ & $37(0.25)$ & $105(0.21)$ & $1.200(0.710-2.027)$ & 0.495 & $0.873(0.633-1.204)$ & 0.407 & \\
\hline $\mathrm{G} / \mathrm{T}+\mathrm{G} / \mathrm{G}$ & $114(0.75)$ & $376(0.75)$ & $1.032(0.6769-1.575)$ & 0.882 & $0.527(0.315-0.881)$ & 0.074 & \\
\hline $\mathrm{MAF}^{\mathrm{d}}$ & 0.50 & 0.48 & & & & & \\
\hline \multicolumn{8}{|l|}{$\mathrm{G} 2$} \\
\hline $\mathrm{T} / \mathrm{T}$ & $27(0.27)$ & $126(0.25)$ & Referent & - & Referent & - & 0.8123 \\
\hline $\mathrm{T} / \mathrm{G}$ & $53(0.52)$ & $271(0.54)$ & $0.913(0.548-1.519)$ & 0.725 & $2.798(1.398-5.597)$ & 0.004 & \\
\hline $\mathrm{G} / \mathrm{G}$ & $21(0.21)$ & $105(0.21)$ & $0.933(0.499-1.746)$ & 0.829 & $1.257(0.836-1.889)$ & 0.269 & \\
\hline $\mathrm{G} / \mathrm{T}+\mathrm{G} / \mathrm{G}$ & $74(0.73)$ & $376(0.75)$ & $0.9184(0.5656-1.491)$ & 0.731 & $2.058(1.090-3.885)$ & 0.026 & \\
\hline $\mathrm{MAF}^{\mathrm{d}}$ & 0.47 & 0.48 & & & & & \\
\hline \multicolumn{8}{|l|}{ G3 } \\
\hline $\mathrm{T} / \mathrm{T}$ & $24(0.14)$ & $126(0.25)$ & Referent & - & Referent & - & 0.0068 \\
\hline $\mathrm{T} / \mathrm{G}$ & $99(0.59)$ & $271(0.54)$ & $1.918(1.171-3.142)$ & 0.0089 & $3.032(1.668-5.510)$ & 0.0003 & \\
\hline $\mathrm{G} / \mathrm{G}$ & $44(0.26)$ & $105(0.21)$ & $2.200(1.256-3.855)$ & 0.0053 & $1.385(0.925-2.074)$ & 0.113 & \\
\hline $\mathrm{G} / \mathrm{T}+\mathrm{G} / \mathrm{G}$ & $143(0.86)$ & $376(0.75)$ & $1.997(1.239-3.218)$ & 0.0040 & $2.330(1.365-3.978)$ & 0.002 & \\
\hline $\mathrm{MAF}^{\mathrm{d}}$ & 0.56 & 0.48 & & & & & \\
\hline
\end{tabular}


Table 2 (continued)

\begin{tabular}{|c|c|c|c|c|c|c|c|}
\hline Genotype & Patients (frequency) & Controls (frequency) & Odds ratio $(95 \% \mathrm{CI})$ & $p^{\mathrm{a}}$ & Adjusted odds ratio $(95 \% \mathrm{CI})^{\mathrm{c}}$ & $p$ & $p_{\text {trend }}$ \\
\hline \multicolumn{8}{|l|}{ Gx } \\
\hline $\mathrm{T} / \mathrm{T}$ & $16(0.26)$ & $126(0.25)$ & Referent & - & Referent & - & 0.8032 \\
\hline $\mathrm{T} / \mathrm{G}$ & $34(0.55)$ & $271(0.54)$ & $0.988(0.526-1.857)$ & 0.970 & $0.988(0.456-2.138)$ & 0.975 & \\
\hline $\mathrm{G} / \mathrm{G}$ & $12(0.19)$ & $105(0.21)$ & $0.900(0.408-1.987)$ & 0.795 & $0.939(0.595-1.483)$ & 0.788 & \\
\hline $\mathrm{G} / \mathrm{T}+\mathrm{G} / \mathrm{G}$ & $36(0.58)$ & $376(0.75)$ & $0.754(0.405-1.405)$ & 0.373 & $1.079(0.537-2.169)$ & 0.831 & \\
\hline MAF $^{\mathrm{d}}$ & 0.47 & 0.48 & & & & & \\
\hline
\end{tabular}

Significant results are highlighted in bold font. NA- the number of genotypes is too small, and therefore, the logistic regression does not apply ${ }^{\mathrm{a}} \chi^{2}$ or ${ }^{\mathrm{b}}$ Fisher's exact test

${ }^{\mathrm{c}}$ ORs were adjusted by age, parity, oral contraceptive use, tobacco smoking, and menopausal status

${ }^{\mathrm{d}}$ Minor allele frequency

Table 3 Distribution of rs6983267 genotypes among SCC risks: parity, oral contraceptive use, tobacco smoking, and menopausal status

\begin{tabular}{|c|c|c|c|c|c|c|c|c|}
\hline \multirow{2}{*}{$\begin{array}{l}\text { High-risk exposure } \\
\text { Genotype }\end{array}$} & \multicolumn{2}{|c|}{ Patients } & \multicolumn{2}{|l|}{ Controls } & \multirow{2}{*}{$\begin{array}{l}\text { Adjusted odds ratio ( } 95 \% \\
\text { CI) } \\
\text { Ever }\end{array}$} & \multirow[t]{2}{*}{$p$} & \multirow{2}{*}{$\begin{array}{l}\text { Adjusted odds ratio (95\% } \\
\text { CI) } \\
\text { Never }\end{array}$} & \multirow[t]{2}{*}{$p$} \\
\hline & Ever & Never & Ever & Never & & & & \\
\hline \multicolumn{9}{|l|}{ Parity } \\
\hline $\mathrm{T} / \mathrm{T}$ & 64 & 40 & 85 & 41 & Referent & & Referent & \\
\hline $\mathrm{T} / \mathrm{G}$ & 242 & 21 & 261 & 10 & $1.212(0.837-1.756)$ & 0.308 & $2.185(0.903-5.289)$ & 0.0797 \\
\hline $\mathrm{G} / \mathrm{G}$ & 114 & 0 & 101 & 4 & $1.377(0.894-2.120)$ & 0.1452 & NA & 0.999 \\
\hline $\mathrm{T} / \mathrm{G}+\mathrm{G} / \mathrm{G}$ & 356 & 21 & 362 & 14 & $1.307(0.915-1.866)$ & 0.1410 & $1.572(0.693-3.565)$ & 0.273 \\
\hline \multicolumn{9}{|c|}{ Oral contraceptive use } \\
\hline $\mathrm{T} / \mathrm{T}$ & 36 & 68 & 53 & 73 & Referent & & Referent & \\
\hline $\mathrm{T} / \mathrm{G}$ & 131 & 132 & 130 & 141 & $1.530(0.935-2.506)$ & 0.0969 & $0.954(0.631-1.443)$ & 0.824 \\
\hline $\mathrm{G} / \mathrm{G}$ & 52 & 62 & 30 & 75 & $1.558(1.135-2.139)$ & 0.0057 & $0.926(0.723-1.186)$ & 0.539 \\
\hline $\mathrm{T} / \mathrm{G}+\mathrm{G} / \mathrm{G}$ & 183 & 194 & 160 & 216 & $1.687(1.048-2.715)$ & 0.0309 & $0.958(0.651-1.409)$ & 0.827 \\
\hline \multicolumn{9}{|l|}{ Smoking } \\
\hline $\mathrm{T} / \mathrm{T}$ & 47 & 57 & 52 & 74 & Referent & & Referent & \\
\hline $\mathrm{T} / \mathrm{G}$ & 106 & 157 & 57 & 214 & $2.098(1.248-3.527)$ & 0.0050 & $0.945(0.631-1.414)$ & 0.781 \\
\hline $\mathrm{G} / \mathrm{G}$ & 20 & 94 & 61 & 44 & $0.599(0.433-0.828)$ & 0.0618 & $1.580(1.218-2.049)$ & 0.065 \\
\hline \multirow[t]{2}{*}{$\mathrm{T} / \mathrm{G}+\mathrm{G} / \mathrm{G}$} & 126 & 251 & 118 & 258 & $1.144(0.713-1.836)$ & 0.575 & $1.263(0.856-1.862)$ & 0.238 \\
\hline & $\begin{array}{l}\text { Pre- } \\
\text { meno- } \\
\text { pausal }\end{array}$ & $\begin{array}{l}\text { Post- } \\
\text { meno- } \\
\text { pausal }\end{array}$ & Premenopausal & $\begin{array}{l}\text { Post- } \\
\text { meno- } \\
\text { pausal }\end{array}$ & Premenopausal & & Postmenopausal & \\
\hline \multicolumn{9}{|l|}{ Menopausal status } \\
\hline $\mathrm{T} / \mathrm{T}$ & 63 & 41 & 55 & 71 & Referent & & Referent & \\
\hline $\mathrm{T} / \mathrm{G}$ & 92 & 171 & 104 & 167 & $0.663(0.422-1.042)$ & 0.183 & $2.362(1.466-3.804)$ & 0.004 \\
\hline $\mathrm{G} / \mathrm{G}$ & 15 & 99 & 35 & 70 & $0.339(0.204-0.563)$ & 0.0723 & $1.797(1.379-2.341)$ & 0.0001 \\
\hline $\mathrm{T} / \mathrm{G}+\mathrm{G} / \mathrm{G}$ & 97 & 280 & 139 & 237 & $0.620(0.335-0.906)$ & 0.0821 & $2.724(1.723-4.307)$ & 0.0002 \\
\hline
\end{tabular}

All $p$ values were adjusted by age. Significant results are highlighted in bold font. NA-the number of genotypes is too small, and therefore, the logistic regression does not apply

T/G vs. T/T was 2.362 (95\% CI 1.466-3.804, $p=0.004)$; for G/G vs. T/T adjusted OR was 1.797 (95\% CI 1.379-2.341, $p=0.0001)$; and for $\mathrm{T} / \mathrm{G}+\mathrm{G} / \mathrm{G}$ vs. $\mathrm{T} / \mathrm{T}$ adjusted $\mathrm{OR}$ was $2.724(95 \%$ CI 1.723-4.307, $p=0.0002)$.
The rs6983267 SNP is associated with increased MYC transcript levels in cervical SCC and non-cancerous tissues

We found statistically significant increase of MYC transcript levels in cervical SCC tissues from carriers of the GG vs. 
T/T $(p<0.00001)$ and G/T vs. T/T $(p=0.0002)$ (Fig. 1a). We also found a statistically significant increase of the MYC transcript levels in the non-cancerous cervical tissues from carriers of the GG vs. T/T ( $p=0.00046)$ but not for G/T vs. $\mathrm{T} / \mathrm{T}(p=0.39)$ (Fig. 1b).

\section{Discussion}

Recent genome-wide association studies (GWASs) have identified rs6983267 in chromosome 8q24 as a new susceptibility locus for several cancers, including breast, prostate, and colorectal cancer [19-21]. It has also been reported that rs6983267 may contribute to the susceptibility to ovarian cancer among premenopausal Chinese women, as well as endometrial and thyroid cancers [22-24]. The rs6983267 SNP has also been significantly associated with susceptibility to lung cancer or platinum-based chemotherapy response [25]. The function of rs6983267 SNP remained elusive, because it was mapped in a gene desert which does not contain any protein encoding genes. The rs6983267 SNP is situated $335 \mathrm{~kb}$ downstream of the MYC proto-oncogene [27, 28]. Several studies have demonstrated a disputable association between rs6983267 and proto-oncogene MYC expression [29-31]. The MYC oncogene is a target gene of the Wnt signaling pathway, which is constitutively activated in the early development of various cancers including CC [32].

In our study, we found an association of rs6983267 SNP with stages III and grade of differentiation G2 and G3. Our observations suggest that the $\mathrm{G}$ variant of rs6983267 SNP induces the spread of cervical SCC cells to the surrounding tissues and promotes rapid growth as compared to lower grade tumor cells. Moreover, we observed significantly upregulated MYC transcript levels in $\mathrm{G} / \mathrm{G}$ as compared to $\mathrm{T} / \mathrm{T}$ carriers in non-cancerous tissues and in carriers of the $\mathrm{G}$ allele as compared to carriers of the $\mathrm{T} / \mathrm{T}$ genotype in the cervical SCC tissues.

Ling et al. [36] demonstrated that long non-coding RNAs (lncRNAs) of Colon Cancer-Associated Transcript 2 (CCAT2), a transcript encompassing the rs6983267 SNP, up-regulates MYC through TCF7L2-mediated transcription. This results in the risk of allele $\mathrm{G}$ of rs6983267 to produce more lncRNAs CCAT2 transcript [33]. Recently, Redis et al. [37] reported that IncRNAs CCAT2 regulates cancer metabolism in vitro and in vivo in an allele-specific manner by binding the Cleavage Factor I (CFIm) complex with distinct affinities for the two subunits CFIm25 and CFIm68 [34]. The 8q24 region also contains lncRNAs CARLo-5, the expression of which has been increased in gastric, colon, lung, and endometrial cancers, where CARLo-5 is used as a modular scaffold [23, 35-38]. The oncogenic rs6983267 polymorphism interacts through long-range mechanism with promoter control CARLo-5 transcription [29]. The IncRNAs are involved in many cellular processes within cancer biology and display tumor suppressive and oncogenic functions in various types of cancer [39].

Moreover, we found an association of increased risk of cervical SCC with rs6983267 SNP in patients with positive history of oral contraceptive use, tobacco smoking, and in women of postmenopausal age. This is in agreement with the previous studies suggesting the causative influence of oral contraceptive use, tobacco smoking, and postmenopausal age in cervical cancer development [8-10].

Our study is the first to demonstrate rs6983267 SNP as a risk factor of cervical carcinogenesis in Caucasian Polish individuals with positive history of oral contraceptive use, tobacco smoking, and postmenopausal age. We also observed that the rs6983267 G variant was associated with increased MYC transcript levels and enhanced growth and spread of cancer cells to neighboring tissues. However, this study should be repeated in other independent cohorts.

Author contributions SŁ: manuscript writing and project development, AL: data collection and analysis, ŻW-F: data collection and analysis, AS: statistics. AT: manuscript writing/editing, AR: project development, SS: tissue collection, and PPJ: project development and editing.

Funding This study was funded by Grant no. 502-01-01124182-07474 from Poznań University of Medical Sciences.

\section{Compliance with ethical standards}

Conflict of interest All authors declare that they have no conflict of interest.

Ethical approval All procedures performed in this study involving were in accordance with the ethical standards of the institutional research committee (nos. 285/16 and 566/16) and with the 1964 Helsinki declaration and its later amendments or comparable ethical standards.

Informed consent Informed consent was obtained from all individual participants included in the study.

Open Access This article is distributed under the terms of the Creative Commons Attribution 4.0 International License (http://creativeco mmons.org/licenses/by/4.0/), which permits unrestricted use, distribution, and reproduction in any medium, provided you give appropriate credit to the original author(s) and the source, provide a link to the Creative Commons license, and indicate if changes were made.

\section{References}

1. Small W Jr, Bacon MA, Bajaj A et al (2017) Cervical cancer: a global health crisis. Cancer 123(13):2404-2412

2. Jhingran A, Kitchener HC, Mileshkin LR et al (2003) Atypical glandular cells. Clin Lab Med 23(3):633-657

3. Walboomers JM, Jacobs MV, Manos MM et al (1999) Human papillomavirus is a necessary cause of invasive cervical cancer worldwide. J Pathol 189(1):12-19 
4. Chatzistamatiou K, Moysiadis T, Angelis E et al (2017) Diagnostic accuracy of high-risk HPV DNA genotyping for primary cervical cancer screening and triage of HPV-positive women, compared to cytology: preliminary results of the PIPAVIR study. Arch Gynecol Obstet 295(5):1247-1257

5. Ault KA (2006) Epidemiology and natural history of human papillomavirus infections in the female genital tract. Infect Dis Obstet Gynecol 2006:1-5

6. Zhang H, Zhang S (2017) The expression of Foxp3 and TLR4 in cervical cancer: association with immune escape and clinical pathology. Arch Gynecol Obstet 295(3):705-712

7. Wang HL, Lu X, Yang X, Xu N (2016) Association of MBL2 exon1 polymorphisms with high-risk human papillomavirus infection and cervical cancers: a meta-analysis. Arch Gynecol Obstet 294(6):1109-1116

8. Kasap B, Yetimalar H, Keklik A et al (2011) Prevalence and risk factors for human papillomavirus DNA in cervical cytology. Eur J Obstet Gynecol Reprod Biol 159:168-171

9. Almonte M, Albero G, Molano M et al (2008) Risk factors for human papillomavirus exposure and co factors for cervical cancer in Latin America and the Caribbean. Vaccine 26:L16-L36

10. Luhn P, Walker J, Schiffman M et al (2013) The role of co-factors in the progression from human papillomavirus infection to cervical cancer. Gynecol Oncol 128(2):265-270

11. Hemminki K, Chen B (2006) Familial risks for cervical tumors in full and half siblings: etiologic apportioning. Cancer Epidemiol Biomark Prev 15(7):1413-1414

12. Yi K, Yang L, Lan Z, Xi M (2016) The association between MTHFR polymorphisms and cervical cancer risk: a system review and meta analysis. Arch Gynecol Obstet 294(3):579-588

13. $\mathrm{Pu} \mathrm{X,} \mathrm{Gu} \mathrm{Z,} \mathrm{Wang} \mathrm{X} \mathrm{(2016)} \mathrm{Polymorphisms} \mathrm{of} \mathrm{the} \mathrm{interleukin} 6$ gene and additional gene-gene interaction contribute to cervical cancer susceptibility in Eastern Chinese women. Arch Gynecol Obstet 294(6):1305-1310

14. Chen D, Juko-Pecirep I, Hammer J et al (2013) Genome-wide association study of susceptibility loci for cervical cancer. J Natl Cancer Inst 105(9):624-633

15. Shi Y, Li L, Hu Z et al (2013) A genome-wide association study identifies two new cervical cancer susceptibility loci at $4 \mathrm{q} 12$ and 17q12. Nat Genet 45(8):918-922

16. Miura K, Mishima H, Kinoshita A et al (2014) Genome-wide association study of HPV-associated cervical cancer in Japanese women. J Med Virol 86(7):1153-1158

17. Mehta AM, Mooij M, Branković I et al (2017) Cervical carcinogenesis and immune response gene polymorphisms: a review. J Immunol Res 2017:8913860

18. Shen C, Liu Y, Shi S et al (2017) Long-distance interaction of the integrated HPV fragment with MYC gene and 8q24.22 region upregulating the allele-specific MYC expression in HeLa cells. Int J Cancer 141(3):540-548

19. Bertucci F, Lagarde A, Ferrari A et al (2012) 8q24 cancer risk allele associated with major metastatic risk in inflammatory breast cancer. PLoS One 7(5):e37943

20. Troutman SM, Sissung TM, Cropp CD et al (2012) Racial disparities in the association between variants on $8 \mathrm{q} 24$ and prostate cancer: a systematic review and meta-analysis. Oncologist 17(3):312-320

21. Wang YP, Zhang J, Zhu HY et al (2014) Common variation rs6983267 at 8q24.1 and risk of colorectal adenoma and cancer: evidence based on 31 studies. Tumour Biol 35(5):4067-4075
22. Han J, Zhou J, Yuan H et al (2017) Genetic variants within the cancer susceptibility region $8 \mathrm{q} 24$ and ovarian cancer risk in Han Chinese women. Oncotarget 8(22):36462-36468

23. Zhao X, Wei X, Zhao L et al (2016) The rs6983267 SNP and long non-coding RNA CARLo-5 are associated with endometrial carcinoma. Environ Mol Mutagen 57(7):508-515

24. Li J, Wang X, Dong J (2016) Association of rs6983267 polymorphism and thyroid cancer susceptibility: a systematic review and meta-analysis. Med Sci Monit 2(22):1866-1871

25. Gong WJ, Yin JY, Li XP et al (2016) Association of well-characterized lung cancer lncRNA polymorphisms with lung cancer susceptibility and platinum-based chemotherapy response. Tumour Biol 37(6):8349-8358

26. Chomczynski P, Sacchi N (1987) Single-step method of RNA isolation by acid guanidinium thiocyanate-phenol-chloroform extraction. Anal Biochem 162:156-159

27. Ahmadiyeh N, Pomerantz MM, Grisanzio C et al (2010) 8q24 prostate, breast, and colon cancer risk loci show tissue-specific long-range interaction with MYC. Proc Natl Acad Sci USA 107(21):9742-9746

28. Pomerantz MM, Ahmadiyeh N, Jia L et al (2009) The 8q24 cancer risk variant rs6983267 shows long-range interaction with MYC in colorectal cancer. Nat Genet 41(8):882-884

29. Prokunina-Olsson L, Hall JL (2009) No effect of cancer-associated SNP rs6983267 in the 8q24 region on co-expression of MYC and TCF7L2 in normal colon tissue. Mol Cancer 6(8):96

30. Shang S, Hua F, Hu ZW (2017) The regulation of $\beta$-catenin activity and function in cancer: therapeutic opportunities. Oncotarget 8(20):33972-33989

31. Takatsuno Y, Mimori K, Yamamoto K et al (2013) The rs6983267 SNP is associated with MYC transcription efficiency, which promotes progression and worsens prognosis of colorectal cancer. Ann Surg Oncol 20(4):1395-1402

32. Ramos-Solano M, Álvarez-Zavala M, García-Castro B et al (2015) Wnt signalling pathway and cervical cancer. Rev Med Inst Mex Seguro Soc 53(Suppl 2):218-224

33. Ling H, Spizzo R, Atlasi $Y$ et al (2013) CCAT2, a novel noncoding RNA mapping to $8 \mathrm{q} 24$, underlies metastatic progression and chromosomal instability in colon cancer. Genome Res 23(9): 1446-1461

34. Redis RS, Vela LE, Lu W et al (2016) Allele-specific reprogramming of cancer metabolism by the long non-coding RNA CCAT2. Mol Cell 61(4):520-534

35. Kim T, Cui R, Jeon YJ et al (2014) Long-range interaction and correlation between MYC enhancer and oncogenic long noncoding RNA CARLo-5. Proc Natl Acad Sci USA 111(11):4173-4178

36. Zhang Y, Ma M, Liu W et al (2014) Enhanced expression of long noncoding RNA CARLo-5 is associated with the development of gastric cancer. Int J Clin Exp Pathol 7(12):8471-8479

37. Luo J, Tang L, Zhang J et al (2014) Long non-coding RNA CARLo-5 is a negative prognostic factor and exhibits tumor prooncogenic activity in non-small cell lung cancer. Tumour Biol 35(11):11541-11549

38. Wang F, Xie C, Zhao W et al (2017) Long non-coding RNA CARLo- 5 expression is associated with disease progression and predicts outcome in hepatocellular carcinoma patients. Clin Exp Med 17(1):33-43

39. Rao AKDM, Rajkumar T, Mani S (2017) Perspectives of long non-coding RNAs in cancer. Mol Biol Rep 44(2):203-218 